\title{
Effect of Cysteine and Lysine on Some Technical Properties of Yoghurt Starter Culture Bacteria
}

\author{
Nasim Azari ${ }^{1 *}$, Hamid Ezzatpanah ${ }^{1}$, Maryam Tajabadi-Ebrahimi $^{2}$, Maryam Mizani $^{1}$ \\ 1.Department of Food Science and Technology, Science and Research Branch, Islamic Azad University, Tehran,Iran \\ 2. Department of Science, Faculty of Science, Tehran Central Branch, Islamic Azad University, Tehran, Iran
}

\section{A B S T R A C T}

Background and Objectives: Enhancing the growth and function of lactic acid bacteria through fortifying the basic ingredient of yogurt, milk ,have always been a key factor in the application as an industrial starter culture. The purpose of the present study is to introduce the application of certain materials in yoghurt milk with the aim of enhancing the growth and acid production, and reduction of fermentation time, optimizing the structure and texture in fermented products as well as reducing starter culture consumption which results in balancing the corresponding expenditures.

Materials and Methods: By using local starter culture consisting Lactobacillus delbruecki ssp bulgaricus and Streptococcus thermophilus in 50:50 ratio, four samples of set yoghurt were prepared in triplicated tests. One sample as a control and three samples were supplemented by L-lysine, L-cysteine and the mixture of the two by $100 \mathrm{mg} / \mathrm{L}$ for each one respectively. The factors were studied based on fermentation time, bacterial viability, acid forming, sensory evaluation and the amount of syneresis and water holding capacity (WHC).

Results: The results showed a significant effect on reducing fermentation time, this factor showed reduction from 260 minute in control sample to 210 minute in samples that were enriched by Lysine and Lysine plus cysteine and 180 minute in cysteine $\mathrm{p} \leq 0.05$, significantly increasing titratable acidity and optimizing viability in enriched samples besides, the end product had firmer structure and a lower syneresis amounts as it was decreased from $4.71 \%$ in control sample to $2.83,2.76$ and $3.06 \%$ in samples that were enriched by lysine, cysteine and both of them respectively $(\mathrm{p} \leq 0.05)$. the same results were found for the best WHC in cysteine fortification $(\mathrm{p} \leq 0.05)$.

Conclusions: Lysine has been responsible for optimization of Streptococcus thermophilus growth. Accordingly, there was an increase in the number of Streptococcus thermophilus to the advantage of Streptococcus thermophilus ratio which later led to a stronger start for fermentation process. On the other hand, as a result of cysteine reduction property enhanced condition for Lactobacillus bulgaricus led to a higher acid production, hence a stronger texture and lower wheying off and better firmness and thickness and finally better sensory evaluation score.

Keywords: Yoghurt milk, Starter culture, Syneresis, Water Holding Capacity

\section{Introduction}

Fermented milks are widely manufactured throughout the world, and approximately 400 generic names are applied to the traditional and commercial products; but the list may include only a few variations(1). Yoghurt starter cultures are a group of lactic acid bacteria which; through conversion of lactose to lactic acid and decrease in $\mathrm{pH}$ value in milk and fermenting it into yoghurt, bring about an increase in shelf life beside adding a more pleasant flavor which will make this fermented milk product consumable for people with lactose-intolerance syndrome(2). These bacteria abound both in nature and dairy products, and a certain number of them create technical property in the product and consist of Lactobacillus delbruecki ssp bulgaricus and Streptococcus thermophilus in ratio 50:50 usually. This property in highly dependent upon their origin where they were isolated. Applying these bacteria with such properties which may be absent in other bacteria not only can create new properties such as a unique flavor, but also can lead to the survival of traditional- local bacteria(3). Several factors, such as 
kind of strains, $\mathrm{pH}$ and acidity levels, presence of other micro-organisms, incubation temperature and time, presence of oxygen, hydrogen peroxide and bacterial metabolites (lactic and acetic acid) have been identified as causing the low counts of starter bacteria in commercial fermented milk products(4-6). In yoghurt as a fermented dairy product, it is generally recognized that Lactobacillus delbruecki ssp bulgaricus is the main core in providing milk protein-deriving amino acids and vital peptides for bacterial growth, and supporting S.thermophilus with weak proteolytic activity while requires different amino acids such as glutamic acid, histidine, methionine, cystine, valine, leucine, tyrosine and lysine(6). Thus proteolytic activity pattern during symbiotic interaction between Lactobacillus bulgaricus and Streptococcus thermophilus in fermentation process is very important, also the presence of exogenous nitrogen source in growth medium is the next essenssial factor(7). Applied basic components in starter culture formulation media usually consist of skim milk powder, demineralized whey protein, dry pancreas extract, lactose, yeast extract, dextrose, etc(8). Controlling production condition and optimizing the end product properties can be achieved by adding certain components to starter media $(9,10)$, for example the presence of phosphate salts such as sodium phosphate, potassium, ammonium phosphate or a mixture of the three can partially control bacteriophage in dairy industry through chelating calcium available to phage (11).

The physical attributes of yogurts, including lower syneresis and perceived viscosity, are crucial aspects of the quality and acceptance by sensory evaluation of this fermented milk product. An understanding of the useful factors in the formation of texture in yogurts and the impact of processing conditions on texture development may help to improve the quality of yogurt.Our objectives have been carrying out a survey on cysteine and lysine to media culture as an optimizing factor for activities of lactic acid bacteria, optimizing the fermenting process and producing more acid quicker,therefore resulting in better quality in end the product.

\section{Materials and Methods}

Yoghurt preparation: A defined volume of recombined milk, consisting $12 \%$ skim milk powder, was pasteurized at 85 Cfor 15 minutes and cooled downby to $44-45 \mathrm{C}$, the temperature at which the starter culture was added $(12,13)$.

The freeze dried starter culture consisting of Lactobacillus delbruecki ssp bulgaricus and Streptococcus thermophilus was isolated and selected from local Iranian yoghurt then in $10^{7} \mathrm{CFU} / \mathrm{ml}$ inoculation dose by 50:50_ ratio between LB and ST, to be used for yoghurt production.
The inoculated yoghurt mix which was supplemented with L-lysine and L-cysteine (Merck, Germany) was divided into four samples:

\section{L-Lysine added at amounts of $100 \mathrm{mg} / \mathrm{L}$,}

2. L-cysteine added at the amounts of $100 \mathrm{mg} / \mathrm{L}$

3 . The mixture of both of the above mentioned amino acids added at amounts of $100 \mathrm{mg} / \mathrm{L}$ per se.

4. Control sample without any fortification.

Poly-ethylene cups were filled by yoghurt samples and incubated at $42 \mathrm{C}$, once $\mathrm{pH}$ reached $4.5 \pm 0.02$, yoghurt samples were transferred into a cold condition at $4 \mathrm{C}(12,13)$.

The time spent for samples to reach the $\mathrm{pH}$ of $4.5 \pm 0.02$ was recorded for each fermentation time in order to samples determine the of additives (12).

After $24 \mathrm{~h}$ cold storage, samples were assessed as below:

A pH meter(Inolab pH 720,Germany), having been calibrated with standard buffer in $\mathrm{pH} 4.0$ and 7.0, was used to determine $\mathrm{pH}$ value of samples.

The titatable acidity was measured through mixing yoghurt sample with $10 \mathrm{ml}$ of distilled water titrated by $0.1 \mathrm{~N} \mathrm{NaOH}$, using $0.5 \%$ phenolphthalein as color indicator $(11,12)$.

Viability of bacteria: Having been diluted with $9 \mathrm{ml}$ of $0.15 \%$ peptone water,one gram of yoghurt sample was completely mixed with a vortex mixer. Subsequent serial dilutions were prepared and viable number enumerated by pour plate techniques. The counts of Lactobacillus delbruecki ssp bulgaricus were assessed on MRS agar in adjusted $\mathrm{pH}$ of 5.2 and then in anaerobic incubation at $37 \mathrm{C}$ for $72 \mathrm{~h}$.Assessed on M17 agar in aerobically incubation at $43{ }^{\circ} \mathrm{C}$ were used for the counts of S.thermophilus. The number of bacteria is given as colony forming units $(\mathrm{cfu} / \mathrm{g})(8$, 12).

Sensory evaluation: Ten trained panelists were selected according to their knowledge on sensory evaluation of dairy products. During training, panelists were asked to identify visual, texturale and flavor attributes of the yoghurt samples. For each training session, all four types of samples were presented to panelists to be identified:

Visual( free whey).

Texture( thickness, chalkiness,lumpiness).

Flavor( cooked, whey, creamy, animal like, metal, fermented, sour, salty, sweet, astringent, aftertaste).

The attribute was qualified by using the Spectrum universal intensity scale from 0 to 15 , where 0 is not detected, and 15 ,extremely strong(14-17).

Syneresis: At first, a cup of set yoghurt was stirred completely and then $30 \mathrm{~g}$ of it was transferred into a $50 \mathrm{ml}$ conical tube.Second, the stirred samples were then centrifuged at $3313 \times \mathrm{g}$ for 15 minutes at 10(Rotin 380, Hettich, Germany).(Rotin 380, 
Hettich, Germany). Finally separated whey was weighted.The syneresis was expressed as the percentage weight of the whey separated from gel over the initial weight of gel(18-20).

Water-Holding Capacity: The water-holding capacity (WHC) was determined with a modified procedure adapted from Remeuf et al. (2003). A sample of about $20 \mathrm{~g}$ of yoghurt (PY) was centrifuged for $10 \mathrm{~min}$ at $5,000 \times \mathrm{g}$ and $20^{\circ} \mathrm{C}$. The whey expelled (WE) was removed and weighed as grams in days 1 , 14 and 28 after storage. The WHC was defined using(21):

$\mathrm{WHC}(\%)=[(P Y-W E) /(P Y)] \times 100$

Statistical analysis: One Way Analysis of variance(ANOVA) test were performed in order to make comparisons among groups determined by Tukey and T.test method. Statistical significance was declared at $\mathrm{p} \leq 0.05$. Statistical analyses were performed with prism of 5 .

\section{Results}

Adding the mixture of L-lysine, L-cysteine and the mixture of the two led to significant increase in bacterial viability in yoghurt samples in comparison to control sample $(\mathrm{p} \leq 0.05)$. In the three fortificated treatments, not only was the number of lactic acid bacteria increased, but also the ratio between Lactobacillus and Streptococcus was increased remarkably to the advantage of Streptococcus (ratio between LB:ST=35:65) and Lactobacillus (ratio between LB:ST=75:25) in lysine and cysteine treated sample respectively .(Table 1.)
In the samples containing a mixture of these two amino acids, it seems that the growth trend of the number of viable Lactobacillus and Streptococcus have been equal. In addition to a significant increase $(p \leq 0.05)$ in the number of bacteria, the ratio remained unchanged 50:50.(Table 1.)

As seen in table 2, acid production in the samples containing lysine and cysteine and the mixture of the two were significantly increased $(\mathrm{p} \leq 0.05)$ and we found higher amounts of acid producing and lower $\mathrm{pH}$ in sample with Lysine, Lysine + cysteine and cysteine respectively,which led to a significant decrease in fermentation time from 260 minutes to 210,180 and 210 minutes in the sample containing Lysine, Lysine + cysteine and cysteine respectively( $\mathrm{p} \leq 0.05)$.(Table 2.)

While syneresis amount in three supplemented samples were significantly decreased in comparison to control samples $(\mathrm{p} \leq 0.05)$ as you can see in table 2 , the amount of weyying off in control sample was $4.71 \%$ which decresed significantly by adding lysine, cysteine and mix of them to $2.83,2.76$ and $3.06 \%$, no significant difference was witnessed among samples supplemented by lysine, cysteine and the mixture of two but the lowest and the best result was found in cysteine fortification.(Table 3.)

The average water holding capacity (WHC) values in yogurts supplemented with amino acids are shown in table 4. Adding cysteine exhibited the highest level of water holding capacity and samples supplemented by lysine and lysine+cysteine were in the next level respectively, whereas low-level WHC was obtained by control $(\mathrm{P}<0.05)($ table 3$)$.

Table 1. Viability of yoghurt starter bacteria in different suppemented samples

\begin{tabular}{lccc}
\hline Sample & ST (CFU/g) & LB(CFU/g) & Ratio ST/LB \\
\hline Yoghurt & $16 \times 10^{7}$ & $18 \times 10^{7}$ & $50: 50$ \\
Yoghurt+Lysine & $70 \times 10^{7}$ & $23 \times 10^{7}$ & $65: 35$ \\
Yoghurt+Cysteine & $19 \times 10^{7}$ & $53 \times 10^{7}$ & $25:: 75$ \\
Yoghourt+Lysine+Cyseine & $48 \times 10^{7}$ & $45 \times 10^{7}$ & $50: 50$ \\
\hline
\end{tabular}

CFU/g:Colony Forming Unit per gram, ST: Streptococcus thermophiles, LB: Lactobacillus Bulgaricus

Table 2.Some technical properties of yoghurt supplemented by different factors.

\begin{tabular}{lccc}
\hline Sample & Titratable acidity $\left({ }^{\circ} \mathrm{D}\right)$ & Fermentation time $(\min )$ & $\mathrm{pH}$ \\
\hline Yoghurt & $88 \pm 0.02^{\mathrm{a}}$ & $260 \pm 0.01^{\mathrm{a}}$ & $4.90 \pm 0.01^{\mathrm{a}}$ \\
Yoghurt+Lysine & $151 \pm 0.01^{\mathrm{b}}$ & $210 \pm 0.01^{\mathrm{b}}$ & $4.43 \pm 0.01^{\mathrm{b}}$ \\
Yoghurt+ Cysteine & $143 \pm 0.01^{\mathrm{b}}$ & $180 \pm 0.02^{\mathrm{b}}$ & $4.50 \pm 0.02^{\mathrm{b}}$ \\
Yoghourt+Lysine+Cyseine & $150 \pm 0.01^{\mathrm{b}}$ & $210 \pm 0.02^{\mathrm{b}}$ & $4.43 \pm 0.01^{\mathrm{b}}$ \\
\hline
\end{tabular}

a,b;Means in the same column, followed by different letters represent significant differences $(\mathrm{P}<0.05)$, value are the average of values.

Table 3.Some structure properties of yoghurt supplemented by different factors.

\begin{tabular}{lcc}
\hline Sample & WHC\%(day: 1) & Syneresis(\%) \\
\hline Yoghurt & $53 \pm 0.01^{\mathrm{a}}$ & $4.71 \pm 0.01^{\mathrm{a}}$ \\
Yoghurt+Lysine & $74 \pm 0.0^{\mathrm{b}}$ & $2.83 \pm 0.02^{\mathrm{b}}$ \\
Yoghurt+Cysteine & $77 \pm 0.01^{\mathrm{b}}$ & $2.76 \pm 0.0^{\mathrm{b}}$ \\
Yoghourt+Lysine+Cyseine & $66 \pm 0.02^{\mathrm{b}}$ & $3.06 \pm 0.01^{\mathrm{b}}$
\end{tabular}

a,b;Means in the same column, followed by different letters represent significant differences $(\mathrm{P}<0.05)$, value are the average of values. 
Results showed the strong gel structure, higher firmness and more consistent texture of yoghurt, the flavor of end products are also of a higher score compared to the control group of panelists which may be because of a higher amount of acidity in samples( $\mathrm{p} \leq 0.05$ ). (Table 3,4,5.)

Free way score in control sample was the lowest (6.2) and the best result completely same to the result of syneresis and WHC level were found for cysteine, blend of them and lysine fortification as 2.6, 2.9 and 3.1 respectively .

The best structure according to the thickness score was found in lysine+cystein sample (7.2), lysine (7.1) and cysteine (6.9), compared to the controls (5.3). The best result for chalkiness were found in control samples .

The sensory evaluation results show no significant difference between fortificated samples and the control ones in cooked, whey,creamy, fermented and aftertaste $(\mathrm{p} \geq 0.05)$ but the control sample had lower score of acidic property $(\mathrm{p} \leq 0.05)$ that can lead to better overall score and higher consumer acceptance in fortificated samples (table 5).

\section{Disc ussion}

In this study it was found that adding certain amount of lysine results in increases the ratio of Streptococcus in bacteria in yoghurt production which due to feed this factor to Streptococcus, as a vital factor that these bacteria for supply it, are completely depend on media culture formulation(7).
Presence of amino acid is highly efficient in Streptococcus activities and this microorganism requires glutamic acid, histidine, methionine, cysteine, valine, leucine, tyrosine and lysine, which cannot produce these essential amino acids therefore depending on exogenous nitrogen sources that utilize peptided proteins from the growth medium by enzymatic activity $(11,13)$. The only strains of S.thermophilus in which any significant envelope associated caseinolytic activity has been detected recently are the three "Asian" strains originating from Mongolia, Japon and India(7). This proteolytic activity is due to a serin proteinase. Thus proteolytic activity pattern during symbiotic interaction between S.thermophilus and L.bulgaricus in fermentation process is very important(6).Also, the protease activity of Lactobacillus will lead to the break-down of casein in symbiotic activity among Lactobacillus and Streptococcus(22). This will cause release of free amino acids such as lysine for Streptococcus which is incapable of producing this particular amino acid(22).

Significant decreases in fermentation time can also be considered because of cysteine oxygen scavenging activity and the fact that it can optimize the function of lactobacillus as the main microorganism in acid production in the process of fermentation in producing yoghurt. Another study reports the addition of growth factors, such as protein hydrolysates to milk results in enhancing the acidification rate and reduces the fermentation time by $25 \%$ to $75 \%$.(12, 22).

Table 4.Visual and texture properties of yoghurt supplemented by different factors

\begin{tabular}{lcccc}
\hline Attribute/sample & Yoghurt & Yoghurt+Lysine & Yoghurt+Cysteine & Yoghourt+Lysine+Cyseine \\
\hline Free whey & $6.2 \pm 0.01^{\mathrm{a}}$ & $3.1 \pm 0.02^{\mathrm{b}}$ & $2.6 \pm 0.01^{\mathrm{b}}$ & $2.9 \pm 0.01^{\mathrm{b}}$ \\
Thickness & $5.3 \pm 0.01^{\mathrm{a}}$ & $7.1 \pm 0.01^{\mathrm{b}}$ & $6.9 \pm 0.01^{\mathrm{b}}$ & $7.2 \pm 0.01^{\mathrm{b}}$ \\
Chalkiness & $4.8 \pm 0.02^{\mathrm{a}}$ & $6.8 \pm 0.01^{\mathrm{b}}$ & $6.5 \pm 0.0^{\mathrm{b}}$ & $6.7 \pm 0.01^{\mathrm{b}}$ \\
Lumpiness & 0 & 0 & 0 & 0 \\
\hline
\end{tabular}

a,b;Means in the same raw, followed by different letters represent significant differences $(\mathrm{P}<0.05)$, value are the average of panel's score.

Table 5.flavor properties of yoghurt supplemented by different factors

\begin{tabular}{lcccc}
\hline Attribute/sample & Yoghurt & Yoghurt+Lysine & Yoghurt+Cysteine & Yoghourt+Lysine+Cyseine \\
\hline Cooked & $1.2 \pm 0.01^{\mathrm{a}}$ & $1.1 \pm 0.02^{\mathrm{a}}$ & $1.2 \pm 0.01^{\mathrm{a}}$ & $1.2 \pm 0.02^{\mathrm{a}}$ \\
Whey & $1.3 \pm 0.01^{\mathrm{a}}$ & $1.1 \pm 0.01^{\mathrm{a}}$ & $1.1 \pm 0.02^{\mathrm{a}}$ & $1.2 \pm 0.01^{\mathrm{a}}$ \\
Creamy & $4.8 \pm 0.01^{\mathrm{a}}$ & $4.8 \pm 0.0^{\mathrm{b}}$ & $4.6 \pm 0.01^{\mathrm{a}}$ & $0.02^{\mathrm{a}}$ \\
Animal- like & 0 & 0 & 0 & 0 \\
Metal & 0 & 0 & 0 & $0.3 \pm 0.01^{\mathrm{a}}$ \\
Fermented & $0.3 \pm 0.02^{\mathrm{a}}$ & $0.3 \pm 0.01^{\mathrm{a}}$ & $0.4 \pm 0.02^{\mathrm{a}}$ & 0 \\
Salty & 0 & 0 & 0 & 0 \\
Sweet & 0 & 0 & $4.9 \pm 0.01^{\mathrm{b}}$ & $4.5 \pm 0.02^{\mathrm{b}}$ \\
Acidic & $2.3 \pm 0.01^{\mathrm{a}}$ & $4.7 \pm 0.01^{\mathrm{b}}$ & 0 & 0 \\
Astrigent & 0 & 0 & $1.7 \pm 0.01^{\mathrm{a}}$ & $1.8 \pm 0.01^{\mathrm{a}}$ \\
Aftertaste & $1.9 \pm 0.02^{\mathrm{a}}$ & $1.8 \pm 0.01^{\mathrm{a}}$ & & \\
\hline
\end{tabular}

a,b;Means in the same raw, followed by different letters represent significant differences $(\mathrm{P}<0.05)$, value are the average of panel's score. 
It has also been reported that applying culture media consisting of undecalcified sweet whey, undecalcified skim milk powder, a nitrogen source and a citrate source has proved to have a higher viability and more acid production in a shorter time(14). In another report, with copper addition to whole milk, it was observed that the fermentation time of yoghurt producing was prolonged, while the post acidification of fermented milk was decreased during cold storage (23)

optimized mouth feel and overall higher score in supplemented with mentioned amino acids in comparison to the control sample were found. Probably presence of growth factors in media culture optimized the growth and bacteria activity which lead to creation of triple strong protein gel structure in yoghurt, at the same time $(16,18)$

The ratio between Lactobacillus and Streptococcus in samples containing cysteine was expected due to the advantage of Lactobacillus which need less aerobic condition for growth $(11,12)$. Lysine and cysteine, are both effective as growth factor on lactic acid bacteria viability of Lactobacillus. On the other hand, cysteine is a sulfuric amino acid as a good nitrogen source for bacteria(7). Owing to its reduction properties, the amount of acceptable soluble oxygen of bacteria, redox potential will be decreased since it functions as oxygen scavenger(24). According to reports, acid production by srater culture composed of Lactobacillus bulgaricus and Streptococcus thermophilus was greatly accelerated by decreasing dissolved oxygen (DO) to almost $0 \mathrm{mg} / \mathrm{Kg}$ in the yoghurt mix and that can be effective on symbiotic relationship between Lactobacillus bulgaricus and Streptococcus thermophilus(11).

The reduction of syneresis and water holding capasity by fortification the media culture is due to strong gel structure, higher firmness, thickness and more consistent texture of yoghurt, leading to better holding capacity of whey in triple gel structure and wheying off happens less frequently(25-27). Better and stronger structure properties can lead to better sensory evaluation and higher overall sensory scores thus better consumer acceptance in fortificated samples in comparitione to control samples was noticed which is in accordance with previous research $(26,28)$

\section{Conclusion}

Improvement in dairy media by Lysine and cysteine as a protein supply that results in sharper and faster acidification and increased activity of bacterial culture is very significant which has commercial valuable to dairy industry . improved activity of culture and increased viability, are factors that speed up the production of fermented dairy products and reduce the amounts of starter culture used in fermentation, stronger structure and higher overall sensory score and better acceptance, in addition shorter fermentation time leads to a decrease in overall energy consumption in dairy industry.

\section{Financial disclosure}

The authors declared no financial interest.

\section{Funding/Support}

The study did not receive any financial support.

\section{References}

1. Mohammadi R, Sohrabvandi S, Mohammad Mortazavian A. The starter culture characteristics of probiotic microorganisms in fermented milks. Eng. Life Sci. 2012;12(4):399-409.

2. Michaylova M, Minkova S, Kimura K, Sasaki T, Isawa K. Isolation and characterization of Lactobacillus delbrueckii ssp. bulgaricus and Streptococcus thermophilus from plants in Bulgaria. FEMS. microbiol .lett. 2007;269(1):160-9.

3. Qin Y, Li J, Wang Q, Gao K, Zhu B, Lv N. [Identification of lactic acid bacteria in commercial yogurt and their antibiotic resistance]. Wei sheng wu xue bao $=$ Acta microbiol. Sin. 2013;53(8):889-97.

4. Saccaro DM, Tamime AY, Pilleggi ALO, Oliveira MN. The viability of three probiotic organisms grown with yoghurt starter cultures during storage for 21 days at $4 \mathrm{C}$.

Int J DairyTechnol.2009;62(3):397-404.

5. Robinson RK. Dairy microbiology handbook: the microbiology of milk and milk products: John Wiley \& Sons; 2005.

6. Urshev Z, Ninova-Nikolova N, Ishlimova D, Pashova-Baltova $\mathrm{K}$, Michaylova M, Savova T. Selection and characterization of naturally occurring high acidification rate Streptococcus thermophilus strains. Biotechnol Biotechnol Equip. 2014;28(5):899-903.

7. Beshkova DM, Simova ED, Frengova GI, Simov ZI, Adilov EF. Production of amino acids by yogurt bacteria. Biotechnol prog. 1998;14(6):963-5.

8. Sodini I, Lucas A, Oliveira M, Remeuf F, Corrieu G. Effect of milk base and starter culture on acidification, texture, and probiotic cell counts in fermented milk processing. J. Dairy Sci. 2002;85(10):2479-88.

9. Colombo M, de Oliveira AEZ, de Carvalho AF, Nero LA. Development of an alternative culture medium for the selective enumeration of Lactobacillus casei in fermented milk. Food microbiol. 2014;39:89-95.

10. Bong D, Moraru C. Use of micellar casein concentrate for Greek-style yogurt manufacturing: Effects on processing and product properties. J Dairy sci. 2014;97(3):1259-69.

11. Dave RI, Shah NP. Effect of cysteine on the viability of yoghurt and probiotic bacteria in yoghurts made with commercial starter cultures. Int Dairy J. 1997;7(8):537-45.

12. Dave RI. Factors affecting viability of yoghurt and probiotic bacteria in commercial starter cultures. Victoria University of Technology. 1998.

13. Tamime AY, Robinson RK. Yoghurt: science and technology: Woodhead Publishing; 1999. 
14. Salvador A, Fiszman S. Textural and sensory characteristics of whole and skimmed flavored set-type yogurt during long storage. J. Dairy Sci. 2004;87(12):4033-41.

15. La Torre L, Tamime A, Muir D. Rheology and sensory profiling of set-type fermented milks made with different commercial probiotic and yoghurt starter cultures. Int J Dairy Tech. 2003;56(3):163-70.

16. Ott A, Hugi A, Baumgartner M, Chaintreau A. Sensory investigation of yogurt flavor perception: Mutual influence of volatiles and acidity. J Agric Food chem. 2000;48(2):441-50.

17. Yilmaz M, Dertli E, Toker O, Tatlisu N, Sagdic O, Arici M. Effect of in situ exopolysaccharide production on physicochemical, rheological, sensory, and microstructural properties of the yogurt drink ayran: An optimization study based on fermentation kinetics. J Dairy sci. 2015;98(3):160424.

18. Kalab M, Allan-Wojtas P, Phipps-Todd BE. Development of microstructure in set-style nonfat yogurt-A review. J Food Struc. 1983;2(1):7.

19. Harwalkar V, Kalab M. Susceptibility of yoghurt to syneresis. Comparison of centrifugation and drainage methods. Milchwissenschaft. 1983.

20. Amatayakul T, Sherkat F, Shah NP. Syneresis in set yogurt as affected by EPS starter cultures and levels of solids. Int J Dairy Tech. 2006;59(3):216-21.

21. Akalın A, Unal G, Dinkci N, Hayaloglu A. Microstructural, textural, and sensory characteristics of probiotic yogurts fortified with sodium calcium caseinate or whey protein concentrate. J Dairy sci. 2012;95(7):3617-28.

22. Walstra P, Walstra P, Wouters JT, Geurts TJ. Dairy science and technology: CRC press; 2005.

23. Hansen EB. Commercial bacterial starter cultures for fermented foods of the future. Int $\mathbf{J}$ food microbiol. 2002;78(1):119-31.

24. Shakerian M, Hadi Razavi S, Khodaiyan F, Ziai SA, Saeid Yarmand M, Moayedi A. Effect of different levels of fat and inulin on the microbial growth and metabolites in probiotic yogurt containing nonviable bacteria. Int $\mathbf{J}$ Food Sci Tech. 2014;49(1):261-8.

25. Marshall VM, Rawson H. Effects of exopolysaccharide-producing strains of thermophilic lactic acid bacteria on the texture of stirred yoghurt. Int $\mathrm{J}$ food sci tech. 1999;34(2):137-43.

26. Bhullar Y, Uddin M, Shah N. Effects of ingredients supplementation on textural characteristics and microstructure of yoghurt. Milchwissenschaft. 2002.

27. Remeuf F, Mohammed S, Sodini I, Tissier J. Preliminary observations on the effects of milk fortification and heating on microstructure and physical properties of stirred yogurt. Int Dairy J. 2003;13(9):773-82.

28. Puvanenthiran A, Williams R, Augustin M. Structure and visco-elastic properties of set yoghurt with altered casein to whey protein ratios. Int Dairy J. 2002;12(4):383-91. 